\title{
The Same of Beauty of Vision: The Common Research of Photography and Painting
}

\author{
Xiaobing Hu${ }^{1}$, Fang Tong ${ }^{2}$ \\ ${ }^{1,2}$ Fine Art School, Anqing Normal University, Anqing 246052, Anhui, China \\ 315698886@qq.com
}

\section{Abstract}

Photography is the use of view frames to leave a moment of beauty; art is to show the beauty of things on the canvas. Both reflect beauty, bearing the artistic beauty of things, they have a very close relationship. Photography and painting need to be carefully observed from the object of expression, and then from the composition, color, lighting and other aspects to express the main body. This is not only a skill, but also requires the author to have his own unique ideas, thinking and unique vision, so as to use the author's "window of the mind" to find something special to resonate with the viewer.

Keywords

photography, painting, hue; light

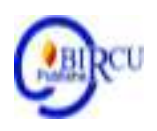

\section{Introduction}

The history of painting has a long history, from the cave murals of ancient times to the various forms of painting today, it in the long river of history in different forms to view the image. Although the history of photography is only 100 years, it is not far from the history of painting, but because of its powerful reproduction function and both practicability and artistry, it has been widely used and developed rapidly. Nowadays, photography is almost an essential firmware in people's lives. It's hard to imagine how beautiful all forms of advertising, life photos and clothing products are in the world without photography. The view frame of a camera and the drawing paper written by a painter are all the artists'" soul windows ".

\section{Review of Literatures}

\section{Effect of Photographic and Painting on Composition}

Composition is the structure of the picture. In the creative activities of composition, from the theme thought to the completion of the artistic image, there must be fresh ideas and unique ideas in order to achieve the perfect unity of content and form. As far as photographic composition is concerned, it is essentially the same as painting, which is the processing and arrangement of the elements of various forms of the picture, so that they can be organically combined on a picture and become a unified whole. This whole perfect picture is not only composed of lines, light and shadow tone, but also according to the requirements of the subject, based on reality, with skilled techniques, to express the vivid, natural and moving image of the objective subject, so that the audience can understand the intention of the photographer. Therefore, composition is an important link for photographers to turn the "image" of nature into the "image" of art. The composition of a photo is an artistic knowledge, not a technical one. It requires photographers to learn to observe their shooting themes and be good at expressing their shooting themes. 
Just as a painter must review his painting object and grasp the characteristics before painting. However, photographic composition also has its own characteristics, for example, photographic composition documentary characteristics, instantaneous characteristics. In addition, photographic composition is also affected by photographic equipment, and it also involves many factors, such as the photographer's ability to observe the objective world and the proficiency in photographic technology.

A successful painting, to some extent, in addition to the choice of appropriate media, is related to the painter's visual grasp and careful arrangement of the picture. In other words, an impressive work is not just a good use of appropriate media. If a painter only stays in the performance skills of the image without paying attention to composition, the elements of the various forms of the picture will not achieve perfect unity. The importance of any work lies in its content and meaning, which depends largely on the painter's unique structure or conception of the picture selection.

The importance of composition, Su Dongpo's poem "horizontal view of the ridge side into a peak, far and near different height" shows the subtlety, that is, when observing the different views of the scene, the picture will show a variety of composition effects and form different picture images. Photography and painting have several commonalities in the composition of visual images. First of all, the composition of visual face, its visual effect has a sense of stability, solemn, solemn. But this composition effect with smooth lines and visual symmetry structure can not help but lack of perspective and appear rigid, which requires the artist's art cultivation. Secondly, in the aspect of side vision, diagonal vision replaces the original parallel line on the picture, and leads the viewer's sight to the depth of artistic conception. From the point of view of image science, the picture enhances the motion of the picture by diagonal vision, which makes the picture vivid and has strong visual impact. Third, the visual aspect of the back needs the artist to put the object into the picture boldly. This visual composition will make the visual language of the picture implicit and infectious, and it is easy to resonate with the viewer emotionally. Of course, the performance of the back is difficult, because the back of the object is usually too "simple ", so, how to" simple "in the excavation of things that are not simple? This requires the subjective effort of the painter. Once you find an unusual flash of light, the whole picture will get a qualitative leap, it will easily catch the eyes of the appreciator, and let it have a different feeling.

\section{Discussion}

\subsection{Color Method for Photography and Painting \\ a. Color Composition Photography and Painting}

A successful photograph or painting must be colored. Specifically, a visual artist who expresses things in color language should have more keen color insight than ordinary people, and can effectively express the observation. Not only that, he must also express human complex emotions through different colors and tissues. This is the tonality problem of color in photography and painting. The sense of order and harmony of color is the premise of forming wonderful picture of photography and painting.

The so-called hue, that is, the overall feeling of the color of the picture, is composed of color brightness, hue and saturation. Different colors have different light and dark differences, there are three types of high-profile, low-key and intermediate tone screen effect. These photography and painting are the same, high-profile photos and high-profile pictures are mainly white, light color and low saturation light color, plus a small amount of dark color composition, which gives people a fresh, elegant, bright feeling; Low-key works 
are mainly dark red, blue and green, give people a deep, quiet, resolute feeling; the middle tone is mostly composed of contrast color, warm color with cold color, light color with bright color, such works give a strong color contrast, tone is clear.

For painting and photography, color not only simply reproduces nature, but also expresses the author's intention. This should pay attention to the relative warmth of different colors, such as red and yellow warm feeling; blue and green with cool feeling. If you want to show the warm theme, choose the warm tone color is appropriate, if the performance of the female theme, choose a gentle, implicit series of colors, such as pink purple, reddish. At the same time, we should pay attention to the relationship between red and green, orange and blue, yellow and purple, which are three pairs of basic complementary colors. Through observation, we can find infinite and rich complementary colors in life, which provides a rich and changeable complementary color horizon for photography and painting.

\subsection{The Tone of Black and White Vision}

If color is focused on tone, then black and white is focused on tone. Shadow tone, originally derived from music, pays attention to the rhythm and rhythm of the picture. In photographic works, the tone of shadow (the tone or tone of the photo), like the sketch of painting, pays attention to the contrast of reality, the relationship between black and white and the level of light and shade in the picture.Hue and shadow tone in painting and photography are the artistic language of the picture. Shadow tone is the life of black and white photography! High-profile black and white photos can give people light, pure and comfortable feelings, high-profile pictures give people beautiful, bright feelings, are often suitable for the performance of bright and beautiful objects. Low-key black and white photos and low-key sketch, can give people mysterious, solemn, melancholy, implicit and other feelings. In the middle tone, the contrast of black and white photos and strong contrast of sketch, often give people a sense of anger, strength, while the weak contrast of the picture and contrast of plain black and white photography, give people a sense of desolation, depression, simplicity. The tone in sketch painting and the tone of color painting are different, sketch is pure use of black, white, gray relationship to do painting, black, white, gray relationship is the essence of sketch painting.

Black and white photography, a colorful, colorful world, with simple black, white, gray tone to express. Sketch is also a simple black and white to express things, according to their subjective will to describe things. The "discoloration" of the two is not a loss, but the transformation of one form of expression into another, which is a kind of artistic expression that becomes concrete and relatively abstract. Compared with color art, black and white photography and sketch painting have more freedom of artistic expression, both in content and form.

"Black and white" is a kind of abbreviation, emphasizes the black and white picture in two essential extreme hue. It is not just black and white, it is actually a reasonable expression of color. In the gray spectrum of black and white gray, there are countless grades. More precisely, the transition from black to white should be hierarchical. A black and white picture is an abstract expression. Nature's rich colors are manipulated by skill and thought to transform them into color elimination. Black has a powerful allure, because we always watch in a visible bright environment, which makes the lowest brightness black always appear particularly noticeable in bright. Black has a distinct heavy feeling, it absorbs all the color light, can stimulate the appreciation of this mysterious color speculation. This is why a night view photo or the darker part of a picture can arouse the viewer's doubts and yearning. White is shown in the black environment, also play a role in 
highlighting the object. The same is true of the bright part of the object in the sketch and the reflective part of the photograph. White, first of all, can make people think of light, because it is the most bright color. Second, it can be considered as the reflection of any smooth object, it is also silver. This gives the viewer a passion, is encouragement, is also the guidance. Therefore, a high-profile photo or high-profile picture will arouse the appreciator's good vision of life and trigger his inner positive feelings. Grey, numerous grades of gray, whether on a black background or a white background, it is always presented as a subject. The creators made every effort to use all kinds of techniques to get a good performance of gray. Level, is for the gray depth of change and set the standard. Perspective is proved by the grey relationship between reality and reality. Harmony is regulated by grey echo. Grey, with rich changing effects, active in black and white photography and sketch pictures in every corner. As long as the authors use it well, to some extent, they have created a good picture effect.

(1) Art design principles in black and white photographs.Black and white photography should pay attention to the distribution of black and white, which coincides with artistic design. Although the distribution of shadow tone can not be specified, there are visual adaptability, psychological adaptability and objective regularity. The sorting of black and white is diverse and is a very complex design. Because of the complexity of the real scene, our arrangement design is more complicated. Some forms we can not think of, because of this, make artistic creation more impulsive, art more attractive. However, during this period, care should be taken to avoid confusion. Concise, neat art design is not equal to monotonous, which requires the author's careful design, even if only black and white tone, there will be refinement and monotony. Creation is the natural expression of the author's inner feelings, both photographers and painters. Simple and able works have no affectation, but mysterious works are different from those carefully carved works. A fake painting can be understood differently and dull, and when we join our own imagination, it becomes meaningful. On the contrary, meticulous work will not be so.

(2) Freehand Chinese painting is a god-oriented "black and white photos ".The author who pays attention to the structure of black and white tone is often freehand brushwork. They regard shadow tone as a language and first. Freehand brushwork does not want the appreciator to get a kind of lesson, vibration or inspiration directly through the content, but shows an artistic appeal through the author's creative emotion, through which the appreciator achieves a kind of lesson. Photography is art, should make the picture as beautiful as possible, the work more into the feelings of the author. So-called, music depends on notes, photography depends on shadow tone. This kind of black and white photography is composed of high quality, unified, subjective tone. The freehand brushwork in Chinese painting also pays attention to the author's emotion, the pen and ink effect, but relatively neglects the body thing. Ink occupies an extremely important position in the whole picture, its thick and light level determines the effect of the picture. The Qing Dynasty Yan Nantian said :" there is a pen and ink called the painting ". That is to say: freehand brushwork pays attention to pen and ink, pen is bone, ink is meat, black and white photos that pay attention to shadow tone complement each other. They are both like a beautiful prose, scattered!

(3) Black-and-white realistic photography is composed of simple, objective and uncarved shadow tones, which truly reproduces the original scene and the original event. The purpose of the photographer is to make people use their energy as much as possible to understand the events or scenes the author wants to talk about. They want people to appreciate not the form, but what the image in the picture is. Painting is also to pay attention to the physical effect of the picture, it requires the painter to first carefully 
observe the object, and then use the most concise "language" to accurately show the object, its strokes are very concise and smooth, so as to successfully shape the image of the object itself, to the extent comparable to the black and white photos. Painting and realistic photography are to arouse the resonance of the viewer.

\subsection{Light Jumps in Photography and Painting}

No light is colorless. Even if a house holds all kinds of colorful objects, once it becomes a dark house without any light, all the colors disappear. Color is not what the object itself exists, but the reaction of light to the object in human vision. Photography is painting with light. Light in painting and photography can create contrast between light and dark and produce a changing color tone. In the picture, light can not only enhance the texture of the texture, but also enhance the appearance of the object. Therefore, photography is the visual art of painting with light, without light, there is no photography. Reasonable use of light can create wonderful effects and enhance the artistic appeal and expressiveness of the works. Since Impressionist painters advocated the art of outdoor sketching and expression, the significance of light to painting has been highlighted, paying attention to the attributes of art and science, and organically combining objects in pictures through their own brushes. Add some subjective understanding to achieve visual resonance with the viewer.

Different attributes of light produce different images in the picture. The hard and soft properties of light bring the vivid and soft visual senses, which will affect the color, shape, tone and beauty of the subject. Because the same object is different in light, the picture presented in front of people is not completely consistent. That's why we can now enjoy Monet's twenty different periods of time to create the "Louang Cathedral" reason! For two different forms of visual art, photography and art, light is like the value of a piece of art, like a person's soul, when the light beats in the picture, the charm and rhythm of the work are presented, and the whole picture will become unusually fresh.

And the role of light in photography is great setting off the theme and rendering the atmosphere. The outline of the object under the strong light is obvious and the contrast is strong; the object under the weak light appears "gentle" a lot. Of course, in the light can be chosen at will, but in order to be suitable for the performance of the subject, the photographer can adjust the light at will, and according to the shooting conditions, the subject is arranged in the best light state. This randomness is also manifested in painting. The light and color in painting are not simple objects. In order to express the artist's inner perception of objects, some subjective light will be used, such as positive light, top light, side light and side light and inverse light.

\section{Conclusion}

A work with vitality can conquer others and pleasure viewers. So, how can this be done to make a work live? This is a problem that every photographer and painter must face. To solve it, we must master certain skills and have certain ability to understand things. And how can this be achieved? When we first see objects, it is the first step of art towards things. It is because of this casual glance that we have a reaction to things, visual art came into being, art began to originate from observation. But note that art is not limited to pure depiction, and therefore, feeling, thought, and judgment are indispensable. Only when observation and skill promote each other, understanding and intuition interact, can the author fully express his voice. 
Both photography and painting are the integration of art and technology. It requires the author to express his thoughts through the quadripartite window. Use various techniques to create a hazy picture according to their own intentions, creating a new era of visual art.

\section{References}

Qu Hui. Practical photography. Chengdu: University of Electronic Science and Technology Press ,1956.

Yang Xiaoli. Modern black and white photography. Beijing: China Workers Press ,1977. Liu Hong. Sketch. Chongqing: southwest normal University Press ,1998.

Ma Yiping. Color. Chongqing: southwest normal University Press ,1998. 